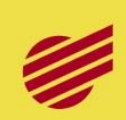

\title{
Numerical simulation of cementitious materials degradation under external sulfate attack
}

\author{
S. Sarkar \\ S. Mahadevan \\ J.C.L. Meeussen \\ H. van der Sloot \\ D.S. Kosson
}

Published in Cement \& Concrete Composites 32 (2010) 241-252 


\title{
Numerical simulation of cementitious materials degradation under external sulfate attack
}

\author{
S. Sarkar ${ }^{\mathrm{a}, 1}$, S. Mahadevan ${ }^{\mathrm{a}, *}$, J.C.L. Meeussen ${ }^{\mathrm{b}, 2}$, H. van $\operatorname{der}_{\text {Sloot }}^{\mathrm{b}, 2}$, D.S. Kosson ${ }^{\mathrm{a}, 1}$ \\ ${ }^{a}$ Dept. of Civil and Environmental Engineering, Vanderbilt University, Nashville, TN 37235, United States \\ ${ }^{\mathrm{b}}$ Environmental Risk Assessment Group, Energy Research Center of the Netherlands, Petten. The Netherlands
}

\section{A R T I C L E I N F O}

\section{Article history:}

Received 18 August 2009

Received in revised form 10 December 2009

Accepted 15 December 2009

Available online 23 December 2009

\section{Keywords:}

Sulfate attack

Cracking

Degradation

Durability

Numerical modeling

\begin{abstract}
A B S T R A C T
A numerical methodology is proposed in this paper to simulate the degradation of cementitious materials under external sulfate attack. The methodology includes diffusion of ions in and out of the structure, chemical reactions which lead to dissolution and precipitation of solids, and mechanical damage accumulation using a continuum damage mechanics approach. Diffusion of ions is assumed to occur under a concentration gradient as well as under a chemical activity gradient. Chemical reactions are assumed to occur under a local equilibrium condition which is considered to be valid for diffusion controlled reaction mechanisms. A macro-scale representation of mechanical damage is used in this model which reflects the cracking state of the structure. The mechanical and diffusion properties are modified at each time step based on the accumulated damage. The model is calibrated and validated using experimental results obtained from the literature. The usefulness of the model in evaluating the mineralogical evolution and mechanical deterioration of the structure is demonstrated.
\end{abstract}

(c) 2009 Elsevier Ltd. All rights reserved.

\section{Introduction}

Low activity nuclear waste is being disposed by mixing with cementitious materials and then being placed in above ground concrete vaults which are to be covered with soil and a final cap to achieve a shallow burial scenario for final disposition. One example of this practice is the disposal of "saltstone" at the Department of Energy Savannah River Site near Aiken, SC [1]. Important potential degradation mechanisms for the saltstone vaults are sulfate attack, carbonation, leaching, alkali-aggregate reaction and reinforcement corrosion. However the present paper is only focused on evaluating degradation of cementitious materials due to ingress of sulfate ions. Effects of the other mechanisms on the sulfate attack phenomenon are not incorporated in the present work. A significant amount of sulfate ions (approximately $24,000 \mathrm{mg} / \mathrm{L}$ [2]) initially is present in the pore solution of the resulting waste form that can potentially leach out of the waste and diffuse into the concrete vault walls which are comprised of steel reinforced

\footnotetext{
* Corresponding author. Address: Box 1831-B, Vanderbilt University, Nashville, TN 37235, United States. Fax: +1 6153223365.

E-mail addresses: sohini.sarkar@vanderbilt.edu(S. Sarkar), sankaran.mahadevan@ vanderbilt.edu (S. Mahadevan), meeussen@ecn.nl (J.C.L. Meeussen), vandersloot@ ecn.nl (H. van der Sloot), david.kosson@vanderbilt.edu (D.S. Kosson).

1 Address: Box 1831-B, Vanderbilt University, Nashville, TN 37235, United States. Fax: +1 6153223365 .

2 Address: Westerduinweg 3 1755LE, Petten, The Netherlands. Fax: +31 224 568163.
}

concrete. The resulting reaction of sulfate with the concrete solid phases and subsequent spalling and cracking of the concrete have been identified as one of the major potential degradation processes for these concrete vaults [3]. Cementitious materials under external sulfate attack expand in volume due to the formation of expansive products, e.g. ettringite [4,5] and gypsum and lose strength due to decalcification of the main cement hydration product (i.e. calcium silicate hydrate) and cracking [6]. If the structure is cracked, the radioactive materials in the waste form can migrate (by diffusion or percolation) through the cracks and be transported to the soil or the groundwater. Similarly, cracking of the cementitious waste form contained within the vault increases the likelihood of percolation through the waste, increasing the rate of contaminant transport to the containing concrete vault. Thus it is important to assess the durability of such structures subjected to aggressive conditions so that engineered systems can be designed such that long-term degradation of contaminant retention structures is minimized and contaminant release rates and extents do not exceed acceptable levels.

When sulfate ions diffuse through a cementitious structure, they react with cement hydration products. Several mineral phases dissolve or precipitate to maintain the equilibrium condition of the pore solution. Some ions also leach out of the structure. Porosity increases or decreases due to the chemical reactions and the resulting dissolution and/or precipitation of specific solid phases, including amorphous gels and discrete minerals. As some or all of the pores within the cement are filled with expansive solid 
phases, strain develops which leads to stress and cracking. This in turn accelerates further diffusion of the ions. Thus the essential components in the degradation of cementitious materials due to the ingress of chemical species are diffusion of ions, chemical reaction, and structural damage. Some numerical models available in the literature simulate diffusion using sophisticated partial differential equations and include a detailed chemical reaction model, but do not include structural damage accumulation [7]. Some models include a continuum damage mechanics based approach to assess the damage of the structure, but do not include detailed diffusion and chemical reaction models [8,9]. Thus it is important to incorporate all the essential components of the degradation mechanism into a single model framework to accurately simulate the behavior of the structures under sulfate attack.

The most common measure of sulfate resistance of cementitious materials is length change of the specimen [10]. Many researchers have attributed the change in length to the amount of ettringite formation $[8,9,11-13]$. But there is no linear relationship between the amount of ettringite formed with the bulk expansion of the specimen [14]. Also, the structure fails due to cracking and loss of strength, which may not have any direct relationship to the bulk expansion of the specimen. Thus it is essential to evaluate the mineralogical features of the specimen with time, as well as damage of the specimen due to precipitation/dissolution of the solids.

In this paper, an integrated numerical modeling approach is developed to evaluate behavior of the structure as a function of time incorporating all three of the essential phenomena mentioned above (i.e. diffusion, chemical reaction and structural damage). The model is calibrated and validated using experimental results available from the literature. The usefulness of the model to evaluate structural damage progression and mineralogical evolution is also demonstrated. Numerical simulations can be performed using the model for a particular set of input parameters (e.g. porosity, tortuosity etc.) to obtain the modeled response of the system for a specified time of interest, e.g. time until failure. Thus the modeling approach presented here can also be used to evaluate the progression of mechanical damage and changes in mineralogical characteristics that occur over very long time periods (e.g. hundreds of years), although further validation is needed and most likely can only be accomplished by inferences drawn from examining structures that have been in place for much shorter time frames and with limited details regarding initial formulation and exposure conditions.

\section{Mechanism of sulfate attack}

The main components of Portland cement are tricalcium and dicalcium silicates, tricalcium aluminate, and tetracalcium aluminoferrite. The cement components react with water and externally added gypsum to form several cement hydration products. In cement chemistry notation, these components are represented as $\mathrm{C}: \mathrm{CaO}, \mathrm{S}: \mathrm{SiO}_{2}, \mathrm{~A}: \mathrm{Al}_{2} \mathrm{O}_{3}, \overline{\mathrm{S}}: \mathrm{SO}_{3}, \mathrm{H}: \mathrm{H}_{2} \mathrm{O}, \mathrm{F}: \mathrm{Fe}_{2} \mathrm{O}_{3}$ etc. [15]. If the hydration is not complete, some of the cement components remain unreacted. Some of the main hydration products are calcium silicate hydrate $(\mathrm{CSH})$, calcium hydroxide or Portlandite $(\mathrm{CH})$, ettringite $\left(C_{6} A \bar{S}_{3} \mathrm{H}_{32}\right)$, calcium monosulfoaluminate $\left(\mathrm{C}_{4} \mathrm{~A} \overline{\mathrm{S}}_{3} \mathrm{H}_{1_{2}}\right)$, hydrogarnet $\left(\mathrm{C}_{3} \mathrm{AH}_{6}\right)$, etc. When sulfate ions penetrate a cementbased structure, a series of reactions take place as shown in Eqs. (1)-(7). The sequential process of reactions is shown in Fig. 1. Sulfate ions react with Portlandite to form gypsum and some calcium aluminate phases to form ettringite (as shown by the light arrows in Fig. 1). Then gypsum reacts with calcium aluminate phases (as shown in the box in Fig. 1), if present, to form ettringite (as shown in bold arrows in Fig. 1). Initially the calcium ions are supplied by

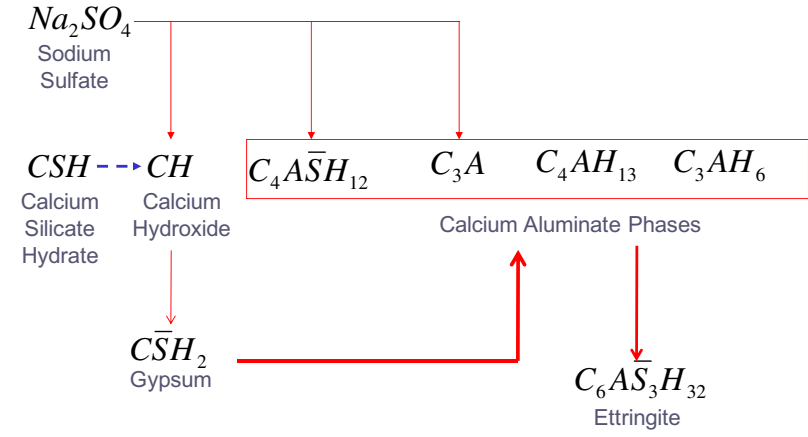

Fig. 1. Schematic diagram of the chemical reactions due to sulfate ingress.

Portlandite. When Portlandite is not available, calcium silicate hydrate dissociates into silica gel, releasing calcium ions (as shown by the dashed arrow in Fig. 1) for ettringite formation [14]. This dissolution process is controlled by chemical equilibria between the solid phases and pore solution and solution conditions controlling calcium saturation in the pore solution.

The main expansive products formed as a result of the reactions are ettringite and gypsum. The changes in volume $\left(\Delta V_{r}\right)$ as a consequence of the chemical reactions with respect to the original volume of the reactants $\left(V_{r}\right)$ are given in Table 1 . Reactions involved in sulfate attack assuming the source of sulfate ions to be sodium sulfate are as follows $[3,8]$ (where $\mathrm{OH}$ indicates hydroxide and otherwise $\mathrm{H}$ indicates $\mathrm{H}_{2} \mathrm{O}$ ):

\section{- Portlandite}

$\mathrm{Na}_{2} \mathrm{SO}_{4}+\mathrm{CH}+2 \mathrm{H} \rightarrow \mathrm{CS} \mathrm{H}_{2}+2 \mathrm{NaOH}$

- Monosulfate

$\mathrm{C}_{4} \mathrm{~A} \overline{\mathrm{S}} \mathrm{H}_{12}+2 \mathrm{C} \overline{\mathrm{S}} \mathrm{H}_{2}+16 \mathrm{H} \rightarrow \mathrm{C}_{6} \mathrm{AS}_{3} \mathrm{H}_{32}$

$3 \mathrm{C}_{4} \mathrm{~A} \overline{\mathrm{S}} \mathrm{H}_{12}+3 \mathrm{Na}_{2} \mathrm{SO}_{4} \rightarrow 6 \mathrm{NaOH}+2 \mathrm{Al}(\mathrm{OH})_{3}+21 \mathrm{H}+2 \mathrm{C}_{6} \mathrm{~A} \overline{\mathrm{S}} \mathrm{H}_{32}$

- Tricalcium aluminate

$\mathrm{C}_{3} \mathrm{~A}+3 \mathrm{C} \overline{\mathrm{S}} \mathrm{H}_{2}+26 \mathrm{H} \rightarrow \mathrm{C}_{6} \mathrm{AS}_{3} \mathrm{H}_{32}$

$\mathrm{C}_{3} \mathrm{~A}+3 \mathrm{Na}_{2} \mathrm{SO}_{4}+3 \mathrm{CH}+32 \mathrm{H} \rightarrow 6 \mathrm{NaOH}+\mathrm{C}_{6} \mathrm{AS}_{3} \mathrm{H}_{32}$

- Tetracalcium aluminate hydrate

$\mathrm{C}_{4} \mathrm{AH}_{13}+3 \mathrm{C} \overline{\mathrm{S}} \mathrm{H}_{2}+14 \mathrm{H} \rightarrow \mathrm{C}_{6} \mathrm{AS}_{3} \mathrm{H}_{32}+\mathrm{CH}$

- Hydrogarnet

$\mathrm{C}_{3} \mathrm{AH}_{6}+3 \mathrm{C} \overline{\mathrm{S}} \mathrm{H}_{2}+2 \mathrm{OH} \rightarrow \mathrm{C}_{6} \mathrm{AS}_{3} \mathrm{H}_{32}$

The change in volume due to the chemical reactions is obtained by subtracting the total volume of the products from the total volume of the reactants (as will be discussed in Section 3). The change

Table 1

Volume change in reactions involved in sulfate attack.

\begin{tabular}{ll}
\hline Reaction & Volume change $\left(\frac{\Delta V_{r}}{V_{r}}\right)$ \\
\hline Eq. (1) & $1.24[3]$ \\
Eq. (2) & $0.55[3]$ \\
Eq. (3) & $0.52[3]$ \\
Eq. (4) & $1.31[3]$ \\
Eq. (5) & $2.83[3]$ \\
Eq. (6) & $0.48[6]$ \\
Eq. (7) & $0.92[3]$ \\
\hline
\end{tabular}




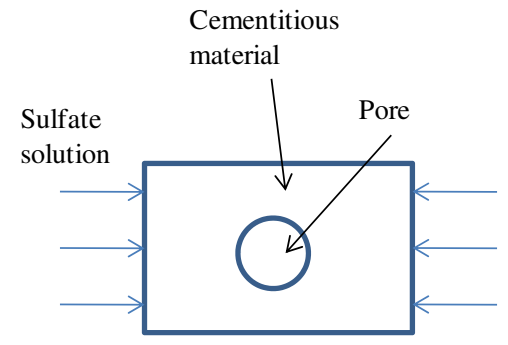

(a)

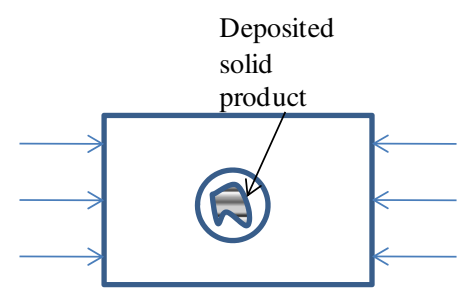

(b)

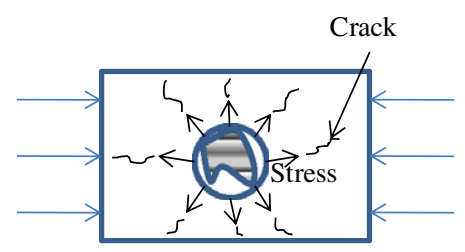

(c)

Fig. 2. Strain and crack development mechanism.

in volume leads to volumetric strain if the volume of the products is greater than the volume of the reactants (as shown in Table 1). The strain developed exerts pressure on the surrounding cement matrix. The structure starts cracking when the stress exceeds the tensile strength of the material. Also, the calcium silicate hydrate dissociation into calcium hydroxide and silica gel results in loss of strength because silica gel is not cohesive. Thus, the net effects of sulfate attack are expansion, cracking and strength loss.

Several hypotheses have been proposed in the past to explain the mechanism of expansion $[14,16]$. Two prominent hypotheses are (i) crystal growth pressure hypothesis, where it is proposed that the expansion is caused by the growth of large ettringite crystals at the cement-aggregate interfaces and cracks and (ii) homogeneous paste expansion hypothesis, where it is proposed that the expansion is caused by the growth of small ettringite crystals throughout the paste $[17,18]$. But neither of the hypotheses is unanimously agreed upon. The model developed in this paper is based on simplifying assumptions required for computational homogenization. It is assumed that the cement hydration products are homogeneously distributed throughout the structure. When sulfate ions diffuse through the structure (Fig. 2a), they react with the cement hydration products. The reaction products are also distributed homogeneously throughout the cement matrix. If the volume of the products is more than the volume of the reactants, the extra volume can only be accommodated in the pore space. The shaded area in Fig. 2b shows the deposited solid product in pore space. The solid product grows in volume as the reaction progresses. When it touches the pore wall, it starts exerting pressure which leads to stress in the material. If the stress is more than the strength of the material, cracks start to form. The solid product does not need to fill up the total pore volume in order to start exerting pressure due to the difference in shape of the deposited solid and the pore as shown in Fig. 2c. Thus it is assumed that only a fraction of the pore volume is available for solid product deposition before strain develops and cracking starts.

\section{Numerical modeling of sulfate attack}

Different models have been developed in the past to numerically simulate the phenomenon of sulfate attack. One of the earliest models was developed by Atkinson and Hearne [11]. This model was based on an empirical relation between volumetric expansion of the structure and the total amount of ettringite formed, developed using experimental results. Following Atkinson and Hearne, Clifton and Pommersheim [3] developed a model from the assumption that volume change in the reaction gives rise to paste expansion which is linearly dependent on the amount of ettringite formed.

A simple micromechanical model developed by Krajcinovic et al. [9] was based on homogenization of microscopic responses on a macro-scale for evaluation of the macro response of the struc- ture. This model was refined recently by Basista and Weglewski [12]. Tixier and Mobasher [8,19] developed a model similar to that developed by Clifton and Pommersheim with a different analytical expression assumed for expansion. The model included a continuum damage mechanics approach to evaluate structural damage and modified the diffusivity assuming that it increases linearly with increasing damage. Bary [20] developed another numerical model incorporating structural damage due to cracking; but only calcium and sulfate concentrations were considered as the dominant species in the model.

Saetta et al. [21] developed a general framework for evaluation of mechanical behavior under physical/chemical attacks. This model evaluated the coupled effects of moisture, heat and chemical species. Evaluation of expansion and cracking due to chemical attack was not included in the model. Another general framework was developed by Schmidt-Dohl and Rostasy [22] which was based on thermodynamic and kinetic considerations for evaluation of degradation of structures under chemical attack. This model can only be used for species with known thermodynamic data. Also, comparison of the mechanical parameters obtained from this model with experimental data posed considerable difficulty. Another general framework was developed by Shazali et al. [23] to evaluate degradation of concrete under sulfate attack but in relation to gypsum formation only. Damage was quantified by a chemical damage parameter (similar to Saetta et al.) and was incorporated to evaluate strength of the specimen.

Samson, Marchand and associates [7,24-26] developed a numerical model for describing the mechanism of ionic transport in unsaturated cement systems. It included ionic diffusion through the use of the extended Nernst-Planck equation, moisture transport and chemical reactions. The model also incorporated the effects of micro-structural changes on the transport properties of chemical species in the cementitious materials using empirical relations based on experimental results. But this model did not consider the changes in the mechanical properties due to cracking and consequent effects on the transport (e.g. diffusive) properties. Gospodinov et al. [27] developed a model which included diffusion of chemical species into cement and the effects of simplified chemical reactions on the changes in porosity. But this model did not include the effects of cracking on the material parameters.

Ping and Beaudoin [28] developed a theoretical model based on chemical-thermodynamic principles. It was assumed that the expansion results from conversion of chemical energy in the form of crystallization pressure to mechanical energy which overcomes the cohesion of the system. The theory was qualitatively validated using experimental results; but it was not quantitatively implemented.

From the perspective of this paper, Tixier's model and Krajcinovic-Basista's model are particularly important as these models evaluate cracking of the structure under sulfate attack using continuum damage mechanics. The general framework of these models is presented in Fig. 3. 
As shown in Fig. 3, diffusion of only sulfate ions was considered in Tixier's and Krajcinovic-Basista's models. Leaching out of the ions from inside of the structure and diffusion coupled with chemical equilibria of other ions present in the external solution were not considered. Expansion of the specimen was assumed to occur due to ettringite formation only; gypsum formation, which is also seen to be expansive $[23,29]$, was not taken into account. Calcium leaching out of the specimen while in contact with water also was not considered in the aforementioned models. This increases the porosity of the structure [30], hence accommodating more ettringite and gypsum before strain can develop. Thus, improved diffusion and chemical reaction models are needed to accurately simulate the behavior of the cementitious materials under chemical attack that are robust enough to consider a broader range of cementitious material formulations and compositions of solutions at the external boundary (i.e. contacting water composition).

The proposed framework of the model incorporating diffusion of additional species, responses to changes in pore structure and more extensive chemical reactions is shown in Fig. 4. In the proposed framework, diffusion of all ions from the external solution and simultaneous leaching out of the ions from inside of the structure are considered. Diffusion and leaching out of ions change the chemical composition of the pore solution which disturbs the local

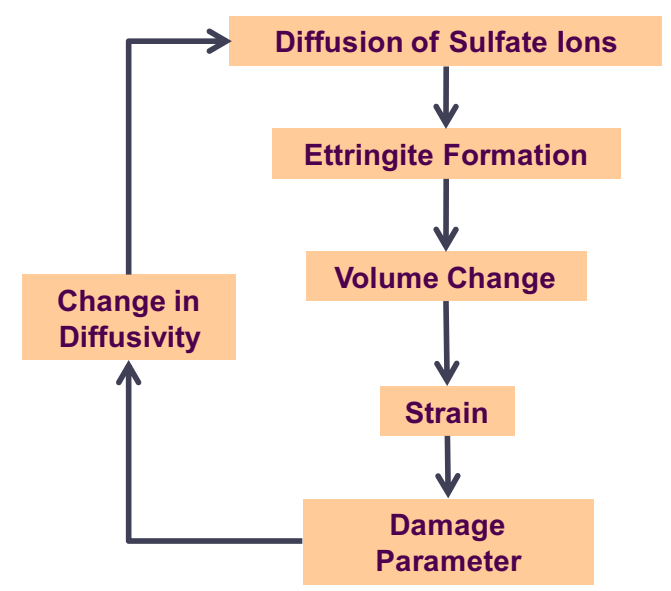

Fig. 3. Components of Tixier's and Krajcinovic-Basista's models.

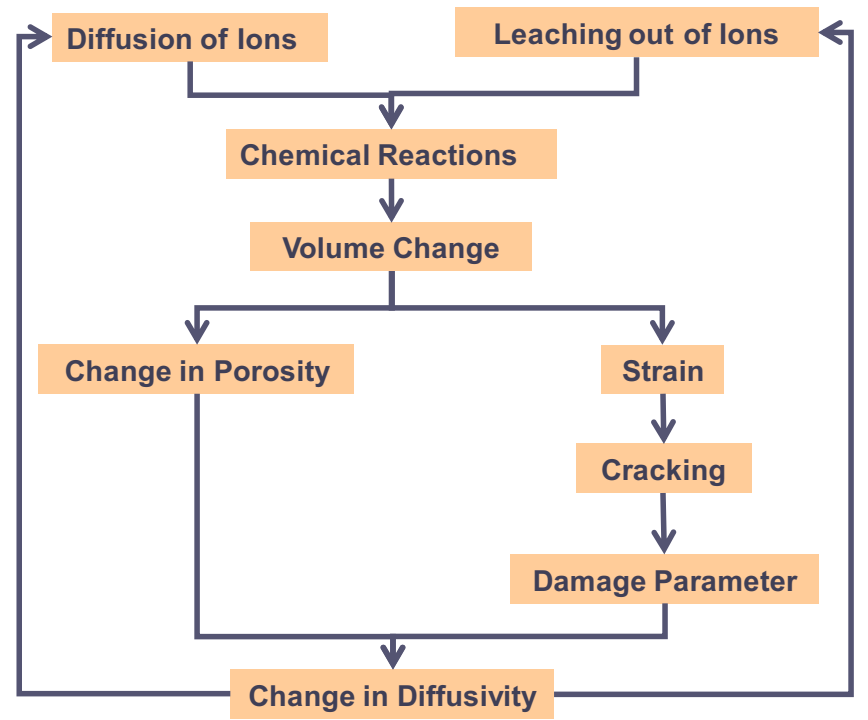

Fig. 4. Overview of the framework developed in this research. equilibrium and thus leads to chemical reactions. These processes are assumed to change the porosity of the structure. Volume change of solid phases due to the chemical reactions leads to change in porosity and strain. Strain leads to cracking of the structure which is reflected in the damage parameter. Change in porosity and cracking are assumed to modify the diffusivity which affects further diffusion of the ions. Thus the developed framework integrates the needed parts for a more robust assessment of degradation of cementitious materials under sulfate attack in a unified framework. The specific approaches used for each phenomenon are described below.

\subsection{Diffusion of ions}

Diffusion of an ion through a saturated porous material under isothermal conditions is modeled by taking into account diffusion of ions under a concentration gradient as well as under a chemical activity gradient, assuming diffusion under electrical potential is negligible $[7,31,32]$. This is expressed as

$\frac{\partial\left(\varphi c_{i}\right)}{\partial t}=\operatorname{div}\left(\frac{D_{i}^{0} \varphi}{\tau}\left(\operatorname{grad}\left(c_{i}\right)+c_{i} \operatorname{grad}\left(\ln \gamma_{i}\right)\right)\right)$

where $c_{i}$ is the concentration of the $i$ th ion, $D_{i}^{0}$ is the free solution diffusivity of the ion, $\varphi$ is the porosity, $\tau$ is the tortuosity and $\gamma_{i}$ is the chemical activity coefficient of the ion. The first term on the right hand side is the rate of diffusion due to the concentration gradient. The second term is the rate of diffusion due to the interactions of ions among each other. If there are $N$ ions present in the system, e.g. $\mathrm{Ca}^{+2}, \mathrm{Na}^{+}, \mathrm{SO}_{4}^{-2}, \mathrm{Mg}^{+2}$ etc., then $\mathrm{N}$ equations are formed for diffusion of all the ions using Eq. (8). These $N$ equations are solved simultaneously in order to obtain diffusion profiles of all the ions. The modified Davies equation [33] is used to calculate the chemical activity of the ions which produces better results for highly concentrated ionic solutions such as concrete pore solutions than other formulations of activity coefficient [34] and is given as

$\ln \gamma_{i}=-\frac{A z_{i}^{2} \sqrt{I}}{1+a_{i} B \sqrt{I}}+\frac{(0.2-4.17 e-5 I) A z_{i}^{2} I}{\sqrt{1000}}$

where $z_{i}$ is the valence of the ion, and $I$ is the ionic strength of the solution expressed as

$I=\frac{1}{2} \sum_{i=1}^{N} z_{i}^{2} c_{i}$

and $A$ and $B$ are temperature dependent parameters given as

$A=\frac{\sqrt{2} F^{2} e_{0}}{8 \pi\left(\varepsilon_{k} R T\right)^{\frac{3}{2}}}$

$B=\sqrt{\frac{2 F^{2}}{\varepsilon_{k} R T}}$

where $e_{0}$ is the electrical charge of one electron $(1.602 \mathrm{E}-19 \mathrm{C})$ and $a_{i}$ is a parameter dependent on the species (assumed to be $3 \mathrm{E}-10 \mathrm{~m}$ as an average value for all the species [33]), $F$ is the Faraday's constant $(96488.46 \mathrm{C} / \mathrm{mol}), R$ is the universal gas constant $(8.3143 \mathrm{~J} /$ $\mathrm{mol} / \mathrm{K}), T$ is the temperature and $\varepsilon_{k}$ is the permittivity of the medium (i.e. water in this case) given as

$\varepsilon_{k}=\varepsilon_{0} \varepsilon_{r}$

where $\varepsilon_{0}$ is the permittivity of the vacuum $(8.854 \mathrm{E}-12 \mathrm{~F} / \mathrm{m})$ and $\varepsilon_{r}$ is the dielectric constant of water (80). The temperature is assumed to be $298 \mathrm{~K}$ for the simulations presented in this paper. The appropriate activity coefficient is then applied to each ion in solution based on the actual speciation of individual ionic forms for each element in solution as calculated as part of the ORCHESTRA 
equilibrium speciation calculations [35] at each node and time step. The activity coefficients are used in Eq. (8) for the calculation of diffusion profiles of the ions and in the chemical equilibrium calculations as discussed in the next subsection.

\subsection{Chemical reactions}

When the ions diffuse through the cementitious material, they react with the cement hydration products. Some solids dissolve or precipitate to maintain the equilibrium state of the pore solution which leads to changes in porosity of the structure. Diffusivity changes due to the changes in porosity as shown in Fig. 4 . The approach adopted for chemical equilibrium calculations, changes in porosity and changes in diffusivity are discussed in this subsection.

Several researchers have used partial differential equations with empirical reaction rate constants combined with Fick's law to simulate diffusion and chemical reactions [8,9,20,23,36,37]. Alternatively, some researchers have used an uncoupled approach to model diffusion and chemical reactions [24] which is computationally more efficient than the coupled approaches [7]. A sequential noniterative approach is used in this paper to couple diffusion and chemical reactions where transport equations are solved first followed by chemical equilibrium calculations. Iterations between these two modules are avoided by using a variable time stepping scheme. The criterion for choosing a time step is restricting the change in mass between two adjacent cells to within $1 \%$ of the total quantities of all the ions present in the cells. The minimum of all the time steps calculated using this method is adopted for the next time step.

A built-in chemical reaction module in a geochemical speciation and transport code, ORCHESTRA [35], is used here to calculate the equilibrium phases of the solids formed/dissolved as a result of the chemical reactions in contact with the pore solution within each unit cell. Consider two species $A$ and $B$ that react to form another species $C$, with the formation reaction as follows:

$a A+b B \rightarrow c C$

At equilibrium, the relation among $A-C$ can be expressed as [34] $(C)^{c}=K_{e q}(A)^{a}(B)^{b}$

where $K_{e q}$ is the equilibrium constant and (...) is the activity of the corresponding species and is expressed as

$(A)=\gamma_{A} c_{A}$

where $\gamma_{A}$ is the activity coefficient as calculated from Eq. (9) and $c_{A}$ is the concentration of $A$. If $N$ number of species are considered, there will be $N$ simultaneous equations which will need to be solved to determine the amount of each species in the system at equilibrium. The resulting system of simultaneous equations along with charge and mass balance equations are solved at each time step.

At each time step, material properties change as chemical reactions alter the composition of the structure. Porosity increases or decreases due to the precipitation and dissolution of the solid phases. The change in porosity is calculated as

$\varphi=\varphi_{0}-\Delta V_{s}$

where $\varphi$ and $\varphi_{0}$ are the current and the initial porosities respectively and $\Delta V_{s}$ is the change in solid volume expressed as

$\Delta V_{s}=\sum_{m=1}^{M}\left(V_{m}-V_{m}^{\text {init }}\right)$

where $M$ is the number of solid phases, $V_{m}^{\text {init }}$ and $V_{m}$ are the initial and current volume of the $m$ th solid. The change in volume is negative (or positive) if the final volume of solids is less (or more) than the initial volume as a result of dissolution (or precipitation) of sol- ids. The pore volume increases (or decreases) as can be calculated from Eq. (17). Diffusivity increases (or decreases) with increase (or decrease) of pore volume. The change in diffusivity due to the change in porosity is calculated using an empirical equation given as [7]

$H_{D}(\varphi)=\frac{e^{\frac{4.3 \varphi}{V_{p}}}}{e^{\frac{4.3 \varphi_{0}}{V_{p}}}}$

where $V_{p}$ is the volume of the paste. Eq. (19) is a correction factor which is multiplied with the diffusivity $\left(\frac{D_{i}^{0}}{\tau}\right)$ in Eq. (8) and is used as the changed diffusivity for the next time step.

The ions present in the pore solution can only react with the species in contact with them through the pore wall. Thus only a fraction of the total amount of the species will be available to the ions in the pore water. The available quantities are obtained from a database/expert decision support system, LeachXS [38]. The database contains results of a large number of experiments performed on a range of cement and mortar compositions. Specimens are crushed to simulate a completely degraded state ( $95 \%$ of the material $<2 \mathrm{~mm}$ in size resembling a completely cracked specimen) and are allowed to leach while in contact with water under different $\mathrm{pH}$ conditions until solid-solution chemical equilibrium is approximated. It is assumed that the maximum leached amount as well as the maximum amount capable of reacting with the pore solution for a particular specimen (i.e. the available quantities) cannot exceed the amount obtained from the experiments. The LeachXS database in conjunction with ORCHESTRA also provides information regarding the mineral phases most likely to be present in the system and required to produce good agreement between the experimental results and model representation for solution concentration of the set of dissolved species (e.g. $\mathrm{OH}^{-}, \mathrm{Ca}^{+2}, \mathrm{SO}_{4}^{-2}$, etc.) as a function of $\mathrm{pH}$ and liquid-to-solid ratio of the extractions.

The chemical reaction module used in this paper is flexible, and allows any number of ions and mineral phases to be included in the numerical framework provided the thermodynamic data for the mineral phases are known (i.e. equilibrium constants as in Eq. (15)).

\subsection{Damage accumulation}

The change in solid volume due to the chemical reactions and the leaching is calculated as in Eq. (18) where the volume of each solid is calculated by multiplying the number of moles of the solid with its molar volume. The molar volumes of the solids considered in this study are shown in Table $2[39,40]$. The change in solid volume leads to development of strain and cracking which changes the diffusivity of the ions as shown in Fig. 4. The approach adopted to relate the changes in solid volume to the formation of cracks is described in this subsection.

The solid products formed as a result of chemical reactions will precipitate in the capillary pores. In the present model, precipitation of solid products in the air voids is neglected. It is assumed that a fraction of the pore volume will be filled before strain starts to develop. This accounts for the fact that ettringite (one of the main expansive products formed as a result of sulfate attack) is a needle shaped structure and it can generate stress as soon as its ends touch the pore wall [41] even if the pore is not completely filled. In general, it accounts for the differences in morphologies of the pore and the precipitated solids. It also accounts for the effect of pore size distribution on solid deposition and does not require distinction amongst pore size domains. Essentially this feature is a model parameter which needs to be calibrated using experimental results. A first estimate of this parameter can be obtained by assuming a fraction of the capillary porosity as ions diffuse mainly through capillary pores and diffused ions interact with 
Table 2

Molar volumes of the mineral phases.

\begin{tabular}{|c|c|c|c|}
\hline Mineral phase & Expanded formula & Common name & Molar volume $\left(\mathrm{cm}^{3} / \mathrm{mol}\right)$ \\
\hline $\mathrm{C}_{6} \mathrm{~A} \overline{\mathrm{S}} \mathrm{H}_{32}$ & $6 \mathrm{CaO} \cdot \mathrm{Al}_{2} \mathrm{O}_{3} \cdot 32 \mathrm{H}_{2} \mathrm{O}$ & Ettringite & 707 \\
\hline $\mathrm{C}_{3} \mathrm{AH}_{6}$ & $3 \mathrm{CaO} \cdot \mathrm{Al}_{2} \mathrm{O}_{3} \cdot 6 \mathrm{H}_{2} \mathrm{O}$ & Hydrogarnet & 150 \\
\hline $\mathrm{C}_{3} \mathrm{FH}_{6}$ & $3 \mathrm{CaO} \cdot \mathrm{Fe}_{2} \mathrm{O}_{3} \cdot 6 \mathrm{H}_{2} \mathrm{O}$ & Fe-hydrogarnet & 155 \\
\hline $\mathrm{C}_{3} \mathrm{ASH}_{8}$ & $2 \mathrm{CaO} \cdot \mathrm{Al}_{2} \mathrm{O}_{3} \cdot \mathrm{SiO}_{2} \cdot 8 \mathrm{H}_{2} \mathrm{O}$ & Stratlingite & 216 \\
\hline $\mathrm{C}_{2} \mathrm{FSH}_{8}$ & $2 \mathrm{CaO} \cdot \mathrm{Fe}_{2} \mathrm{O}_{3} \cdot \mathrm{SiO}_{2} \cdot 8 \mathrm{H}_{2} \mathrm{O}$ & - & 227 \\
\hline $\mathrm{C}_{1,67} \mathrm{SH}_{2.1}$ & $1.67 \mathrm{CaO} \cdot \mathrm{SiO}_{2} \cdot 2.1 \mathrm{H}_{2} \mathrm{O}$ & Jennite & 78 \\
\hline $\mathrm{C}_{0.83} \mathrm{SH}_{1.3}$ & $0.83 \mathrm{CaO} \cdot \mathrm{SiO}_{2} \cdot 1.3 \mathrm{H}_{2} \mathrm{O}$ & Tobermorite-II & 59 \\
\hline $\mathrm{CH}$ & $\mathrm{CaO} \cdot \mathrm{H}_{2} \mathrm{O}$ & Portlandite & 33 \\
\hline $\mathrm{S}$ (amorphous) & $\mathrm{SiO}_{2}$ & Silica gel & 29 \\
\hline $\mathrm{CSH}_{2}$ & $\mathrm{CaO} \cdot \mathrm{SO}_{3} \cdot 2 \mathrm{H}_{2} \mathrm{O}$ & Gypsum & 75 \\
\hline $\mathrm{C}_{4} \mathrm{~A} \overline{\mathrm{S}} \mathrm{H}_{12}$ & $4 \mathrm{CaO} \cdot \mathrm{Al}_{2} \mathrm{O}_{3} \cdot \mathrm{SO}_{3} \cdot 12 \mathrm{H}_{2} \mathrm{O}$ & Calcium monosulfoaluminate & 309 \\
\hline $\mathrm{Al}(\mathrm{OH})_{3}$ (amorphous) & - & Gibbsite & 32 \\
\hline $\mathrm{C}_{2} \mathrm{~S}_{2.4} \mathrm{H}_{3.2}$ & $2 \mathrm{CaO}_{2} \cdot 4 \mathrm{SiO}_{2} \cdot 3.2 \mathrm{H}_{2} \mathrm{O}$ & Tobermorite-I & $59^{*}$ \\
\hline $\mathrm{Fe}(\mathrm{OH})_{3}$ (microcrystalline) & - & Ferric hydroxide & 34 \\
\hline $\mathrm{Na}_{2} \mathrm{SO}_{4}$ & - & Sodium sulfate/mirabilite & 220 \\
\hline
\end{tabular}

It is assumed that the molar volume of Tobermorite-I $\left(\mathrm{C}_{2} \mathrm{~S}_{2.4} \mathrm{H}_{3.2}\right)$ is the same as Tobermorite-II $\left(\mathrm{C}_{0.83} \mathrm{SH}_{1.3}\right)$ due to lack of data.

the solids surrounding the capillary pores. Let us assume the fraction of porosity to be $b$. The net solid volume change contributing to strain development is then calculated as

$\overline{\Delta V_{s}}=\Delta V_{s}-b \varphi V$

where $V$ is the volume of the representative volume element. Clifton and Pommersheim [3] assumed that expansion and cracking will not start until all of the pore volume is filled up by reaction products which leads to $b=1$. Tixier and Mobasher [19] estimated the value of $b$ to be between 0.05 and 0.45 by calibrating the model response using experimental results, Basista and Wegnewski [37] assumed it to be 0.5 . Denham [42] estimated the maximum porosity loss under different scenarios to be $34 \%$ by performing numerical simulations and it was concluded that fracture will only start occuring if the amount of porosity available is $\leqslant 34 \%$ of its initial value. More pore volume is available for solid product deposition if $b$ is greater, leading to delayed initiation of cracking. Similarly, initiation and rate of crack progression is faster if $b$ is smaller.

If $\overline{\Delta V_{s}}>0$, volumetric strain can be calculated as

$\bar{\varepsilon}=\frac{\overline{\Delta V_{s}}}{V}$

Otherwise, strain is zero. Assuming that the material is isotropic, uniaxial strain is calculated as

$\varepsilon=\frac{\bar{\varepsilon}}{3}$

Cracks start to form once the stress corresponding to the strain calculated from Eq. (22) exceeds the tensile strength of the material. A continuum damage mechanics based model is used to relate the cracked state of the structure to the strain calculated from Eq. (22). The cracked state of the structure is manifested in a scalar quantity known as a damage parameter. Conceptually, the damage parameter used here can be interpreted as the surface density of material defects [21] and it can be expressed as the ratio of the damaged area (area of the crack) to the original area [21,43] as shown in Fig. 5. Several formulations are available in the literature which relate strain/stress to the damage parameter [44-48]. The approach used in this paper is described in the following paragraphs.

A qualitative stress-strain diagram for cementitious materials under tensile stress is shown in Fig. 6. Cementitious materials contain pores and micro-cracks which do not affect the strength of the structure in the elastic region (segment OA in Fig. 6). In the nonlinear ascending region (segment $A B$ in Fig. 6), new micro-cracks form which finally coalesce at $B$ to form macro-cracks leading the struc- ture to failure defined by the nonlinear descending curve. In the nonlinear ascending region, the damage parameter $\omega$ is related to the Poisson's ratio (if a load is applied in the longitudinal direction of a specimen, then the Poisson's ratio can be expressed as $\left.v=-\frac{\text { Lateral strain }}{\text { Longitudinal strain }}\right)$ of the damaged structure for a three-dimensional case and the density of the nucleated cracks $C_{d}$ [43]. $C_{d}$ combines the information about the number and the size distribution of the cracks per unit volume of the material and can be expressed as [43]

$C_{d}=k\left(1-\frac{\varepsilon^{t h}}{\varepsilon}\right)^{m}, \quad$ for $\varepsilon>\varepsilon^{t h}$

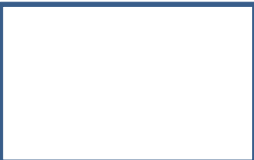

Undamaged area: A

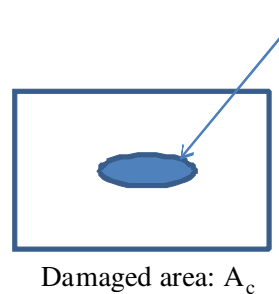

$\omega=\frac{A_{c}}{A}$
Cracked area: $\mathrm{A}_{\mathrm{c}}$

Fig. 5. Schematic diagram depicting concept of damage parameter.

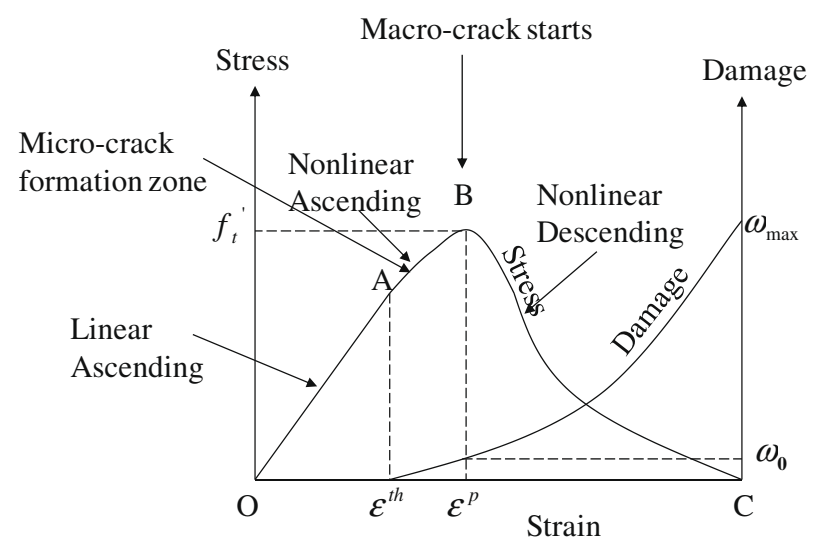

Fig. 6. Stress-strain diagram of concrete under tension [6]. 
where $\varepsilon$ is the strain, $\varepsilon^{\text {th }}$ is the threshold strain at which the microcracks start forming, and $k$ and $m$ are model parameters that need to be calibrated from the experimental stress-strain diagram following the procedure given below.

In the nonlinear ascending region of the stress strain diagram, an equivalent Young's modulus $(E)$ can be expressed as

$$
E=E_{0}(1-\omega)
$$

where $E_{0}$ is the Young's modulus obtained as the initial tangent or the slope of the linear part of the curve (segment OA in Fig. 6) and $\omega$ is the damage parameter. For the uniaxial case, stress $(\sigma)$ and strain $(\varepsilon)$ in the nonlinear region can be related as

$\sigma=E_{0}(1-\omega) \varepsilon$

Assuming that the damage parameter is not affected by the Poisson's ratio of the damaged structure for a one-dimensional simulation, $\omega$ can be expressed as $[43,49]$

$\omega \approx \frac{16}{9} C_{d}$

Combining Eqs. (23)-(26) the following expression can be obtained as

$\sigma=E_{0}\left[1-\frac{16}{9} k\left(1-\frac{\varepsilon^{t h}}{\varepsilon}\right)^{m}\right] \varepsilon$

From Eq. (27) and the stress strain diagram obtained from the experimental data, $k$ and $m$ can be calibrated using a least squares curve fitting method.

The post-peak stress and deformation of the structure (segment $\mathrm{BC}$ in Fig. 6) are modeled by using the relations proposed by Nemat-Nasser and Hori $[8,50]$ based on fracture mechanics and are given as

$\frac{\sigma}{f_{t}^{\prime}}=\sqrt{\frac{\tan \left(\frac{\pi \omega_{0}}{2}\right)}{\tan \left(\frac{\pi \omega}{2}\right)}}$

$$
\frac{w}{w_{0}}=\frac{\sigma}{f_{t}^{\prime}} \frac{\log \left[\sec \left(\frac{\pi \omega}{2}\right)\right]}{\log \left[\sec \left(\frac{\pi \omega_{0}}{2}\right)\right]}-1
$$

where $f_{t}^{\prime}$ is the maximum tensile stress, $\omega_{0}$ is the damage parameter corresponding to the peak stress, $w$ is the post-peak deformation $\left(=\left(\varepsilon-\varepsilon_{p}\right) d x\right.$ where $d x$ is the thickness of the cell $)$ and $w_{0}$ is the deformation corresponding to the peak stress $\left(=\varepsilon_{p} d x\right)$. A relation between the damage parameter and the deformation of the structure can be obtained by combining Eqs. (28) and (29).

\subsection{Change in mechanical and diffusion properties}

Mechanical and diffusion properties change due to the presence of the cracks. In the literature, the effect of the cracks on the material properties has been studied using effective continua or mean field models when the density of the cracks is sparse [51] (referred to as mean field regime). The modified relation between the diffusivity and the crack density parameter in this regime can be expressed as $[9,37]$

$D_{i}=\frac{D_{i}^{0}}{\tau}\left(1+\frac{32}{9} C_{d}\right)$

Similar linear relations between the elastic moduli (Young's modulus and Poisson's ratio) and the damage parameter are also derived as $[9,37]$

$E=E_{0}\left(1-\frac{16}{9} C_{d}\right)$
$v=v_{0}\left(1-\frac{16}{9} C_{d}\right)$ where $E_{0}$ and $v_{0}$ are the initial Young's modulus and Poisson's ratio. Eqs. (30)-(32) are derived based on a self-consistent method which is not valid once macro-cracks start forming and propagating through the structure (referred to as the percolation regime). In this region, the scaling law for diffusivity is given as $[9,37,52]$

$D_{p} \propto\left(C_{d}-C_{d c}\right)^{\mu}$

where $C_{d c}$ is the conduction percolation threshold below which the concentration of cracks is sparse and $\mu$ is a universal exponent $(=2$ for three-dimensional cases). The percolation threshold was determined to be 0.182 using numerical simulation for a specimen with randomly oriented penny shaped cracks by Charlaix [53]. It is assumed by Krajcinovic et al. [9] that a parallel connection exists between the nonintersecting micro-cracks still present in the system and the growing macro-cracks. Thus the overall diffusivity is calculated as $[9,37]$

$D_{i}=\frac{D_{i}^{0}}{\tau}\left[\left(1+\frac{32}{9} C_{d}\right)+\frac{\left(C_{d}-C_{d c}\right)^{2}}{\left(C_{d e c}-C_{d}\right)}\right]$

where $C_{d e c}$ is the rigidity percolation threshold at which the cluster of cracks transects the volume. At the rigidity percolation threshold, the strength of the structure vanishes. The rigidity percolation threshold was determined to be 0.712 using numerical simulation by Sornette [54]. The effect of damage on the elastic moduli in this regime is not well investigated in the literature. Thus Eqs. (31) and (32) are assumed to be valid in the percolation regime as well which modifies the rigidity percolation threshold to $9 / 16$, at which point $E$ and $v$ become zero $[9,37]$.In summary, the model described here combines multi-ionic diffusion with chemical equilibrium calculations and continuum damage mechanics. The model can be used to predict distribution profiles of the various ions in solution and solid phases. Also, the progression of damage in space and time can be simulated, which then can be used to assess the durability of the structure.

\section{Simulation results}

\subsection{Model calibration and validation}

Data on a test specimen was obtained from the literature [7,55]. The specimen consisted of CSA Type 10 cement with water-cement ratio 0.6 and density $1742 \mathrm{~kg} / \mathrm{m}^{3}$. Porosity of the specimen is experimentally found to be 0.52 by Samson and Marchand [7] and this value is used in the simulations. The specimen was a $7 \mathrm{~cm}$ diameter disk of height $20 \mathrm{~mm}$ which was cured for 28 days and then immersed in $30 \mathrm{~L}$ of $50 \mathrm{mmol} / \mathrm{L} \mathrm{Na}_{2} \mathrm{SO}_{4}$ solution for a year. All the faces of the sample were sealed except for one circular face so that diffusion can be simplified as a net one-dimensional phenomenon. The external solution was renewed every 7 days. The initial $\mathrm{pH}$ of the pore solution is calculated to match the initial $\mathrm{OH}^{-}$concentration as given in [7] and is used in the simulations. The comparison between the initial pore solution composition as computed by the proposed model and that experimentally determined by Samson and Marchand [7] is given in Table 3. The calcium and sulfur profiles were measured at the end of 3 months, 6 months and 1 year. Model calibration parameters are the fraction of porosity available for solid product deposition, i.e. $b$ in Eq. (20), and tortuosity. The calibrated values were found to be 0.3 and 35 for $b$ and tortuosity, respectively, to fit the experimental results of 3 months. The total available concentrations of the different species are obtained for a Portland cement paste of similar composition from the LeachXS database. Fifteen minerals are considered for dissolution/precipitation as shown in Table 2. The CSH phase is modeled using the 'solid solution model' developed by Kulik and Kersten [39,56]. The model is based on the assumption that 
Table 3

Comparison of pore solution compositions.

\begin{tabular}{lll}
\hline Ions & $\begin{array}{l}\text { Computational results of } \\
\text { proposed model (mmoles/L) }\end{array}$ & $\begin{array}{l}\text { Experimental results by Samson } \\
\text { and Marchand [7] (mmoles/L) }\end{array}$ \\
\hline $\mathrm{OH}^{-}$ & 465.0 & 429.3 \\
$\mathrm{Na}^{+}$ & 215.4 & 111.1 \\
$\mathrm{~K}^{+}$ & 273.1 & 327.0 \\
$\mathrm{SO}_{4}^{-2}$ & 3.45 & 5.6 \\
$\mathrm{Ca}^{+2}$ & 1.03 & 1.3 \\
$\mathrm{Al}(\mathrm{OH})_{4}^{-}$ & 0.17 & 0.2 \\
\hline
\end{tabular}

the $\mathrm{CSH}$ phase can be described by two concurrent solid solution systems (i) mixture of amorphous silicon dioxide $\left(\mathrm{SiO}_{2}\right)$ and Tobermorite-I $\left(2 \mathrm{CaO}_{2} \cdot 4 \mathrm{SiO}_{2} \cdot 3.2 \mathrm{H}_{2} \mathrm{O}\right)$ and (ii) mixture of Jennite $\left(1.67 \mathrm{CaO} \cdot \mathrm{SiO}_{2} \cdot 2.1 \mathrm{H}_{2} \mathrm{O}\right)$ and Tobermorite-II $\left(0.83 \mathrm{CaO} \cdot \mathrm{SiO}_{2}\right.$. $\left.1.3 \mathrm{H}_{2} \mathrm{O}\right)$. The calibration results are shown in Fig. 7.

Experimental profiles (solid lines) for calcium and sulfur and the simulation results (solid-dotted lines) shown in Figs. 7 and 8 were obtained from Samson and Marchand [7]. The experimental results performed by SIMCO technologies, Canada were scaled to match the simulation results performed using STADIUM software by Samson and Marchand [7]. The simulations performed using the model developed in this paper (shown as dashed lines) are seen to qualitatively match with the experimental results. The initial conditions used in Samson and Marchand are based on the mass conservation law (equating amount of each species in the cement with that in the probable solid phases) whereas the initial conditions for the current simulations are obtained by attaining thermodynamic equilibrium along with the conservation of mass of each species in the cement and in the potential solid phases (mass conservation law as described above). The calibrated model as developed here then was used to validate the model responses at the end of 6 months and 1 year using the experimental results as shown in Fig. 8. The experimental results are the total concentrations of calcium and sulfur present as solid phases in the system. The model uses the available quantities (i.e. readily leachable) of the species to calculate the solid compositions in the system as mentioned earlier. Thus the total quantities are calculated by adding the unavailable quantities (=total quantity - available quantity) to the simulation results. As the values at a very small distance inside the structure $(x=\delta)$ are not known, the unavailable quantities are plotted at $x=0$. In Figs. 7 and 8, the calcium profiles show a decrease in concentration near the boundary due to leaching of calcium to the outside solution. The peaks in the sulfur profiles occur due to the formation of gypsum which are followed by ettringite formation, which can be identified as a further reduction in sulfur concentration in Figs. 7b and $8 \mathrm{~b}$ and $d$. Thus, the mineralogical evolution can be predicted from the numerical simulations, as well as the damage progression as presented below.

The maximum value of the damage parameter for the purpose of the above simulations is assumed to be 0.9 instead of 1 to allow for the additional system uncertainties and adequate margin in 'design' performance. The damage front progression for the experimental case simulated is estimated by the depth up to which all the elements are calculated to be cracked (i.e. damage parameter reaching its maximum value of 0.9 ) at the simulation time corresponding to the experimental results. The damage front is calculated to be at $1.4 \mathrm{~mm}$ and $2.4 \mathrm{~mm}$ from the specimen boundary based on the numerical simulation after 6 months and 1 year, respectively as shown in Fig. 9. The drop in the damage parameter at approximately $1.2 \mathrm{~mm}$ as seen in the damage parameter profiles at the end of 6 months and 1 year is due to the fact that calcium leaching (which occurs simultaneously with cracking due to expansive product formation) increases porosity before the element is completely cracked. It is important to note that damage occurs not at the structure surface, but rather at some depth from the surface as a combined result of calcium leaching and sulfate attack. The indicated depth of the initial damage is suggestive of the spalling depth generally observed in the literature, but this needs to be experimentally verified. The sample used in the reported experiment had a large porosity value $(=0.52)$ which allows for more solid product deposition before strain develops. Cement mortar and concrete samples generally have much smaller porosities (0.10.3 ). Thus strain develops more easily in the case of cement mortar and concrete samples than in cement paste samples with high water-cement ratio.

\subsection{Damage progression}

Damage may not be a significant factor for short term performance, but it can affect the long-term durability of structures and therefore needs to be considered through numerical simulations. A structure fails under sulfate attack due to cracking, thus requiring consideration of the cracking progression as a function of initial conditions (i.e. formulation) and external conditions. The usefulness of the numerical modeling framework developed in this paper in evaluating damage progression and subsequent failure of a structure is illustrated next.

A numerical simulation is performed on an example case to demonstrate the progression of damage in space and time. The

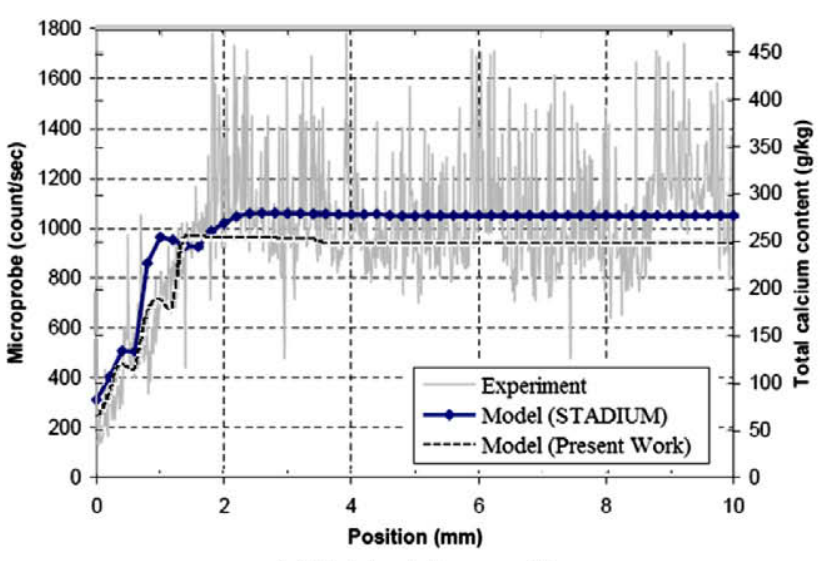

(a) Total calcium profile

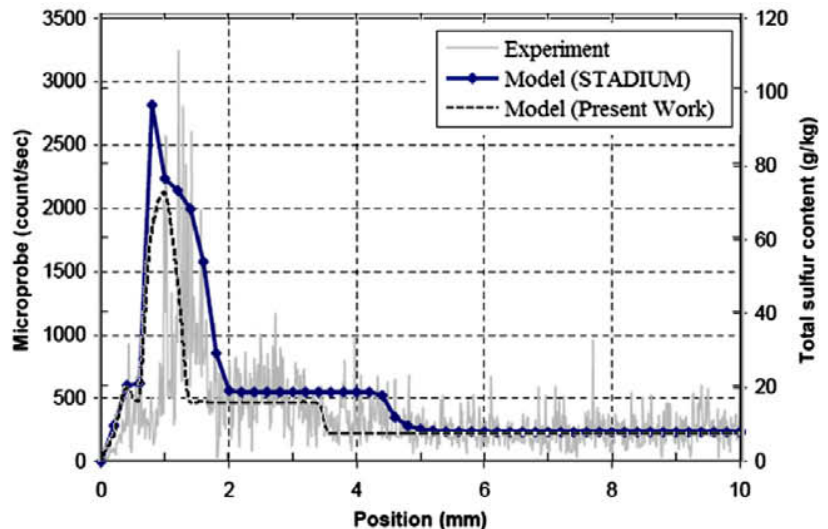

(b) Total sulfur profile

Fig. 7. Total calcium and sulfur profiles in solid phases at the end of 3 months after Samson and Marchand [7] 


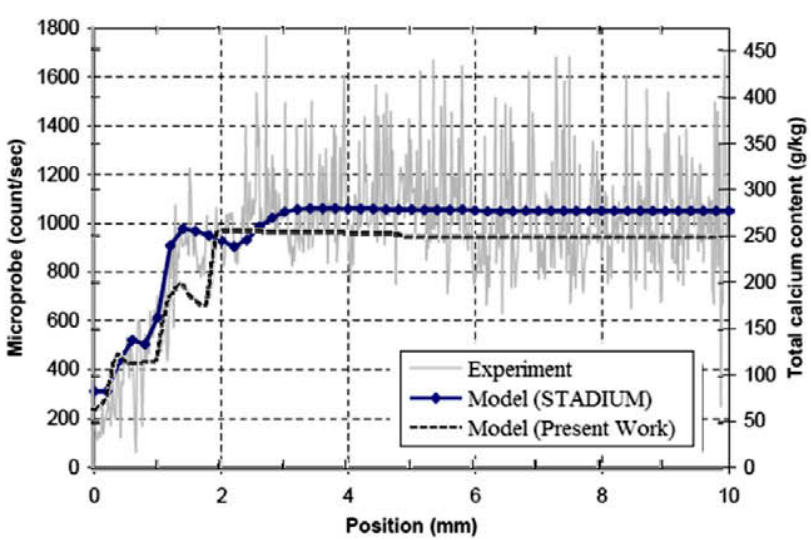

(a) Total calcium profile

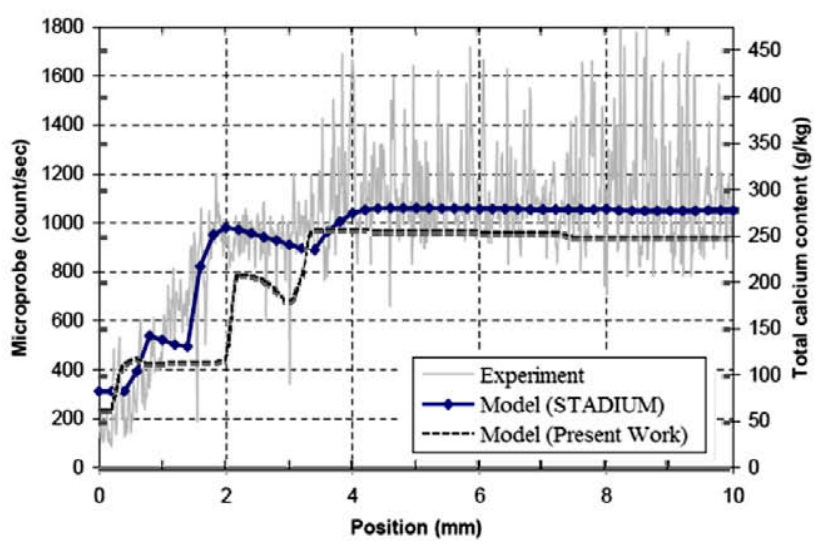

(c) Total calcium profile

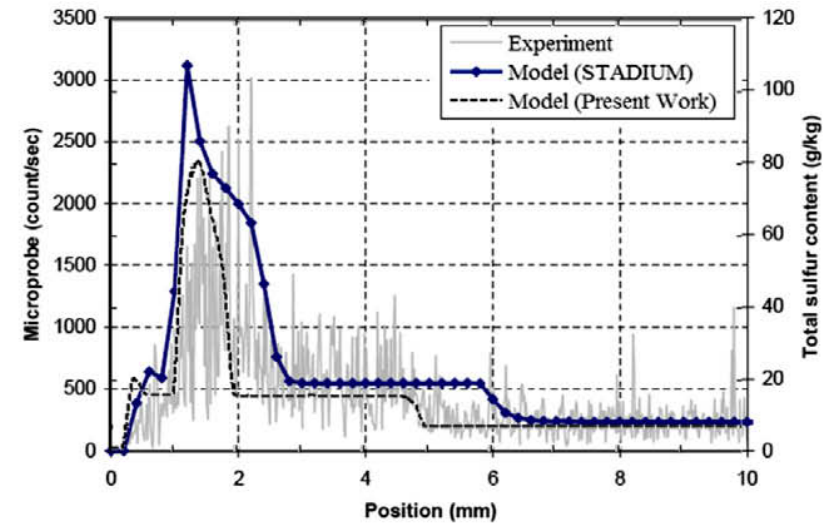

(b) Total sulfur profile

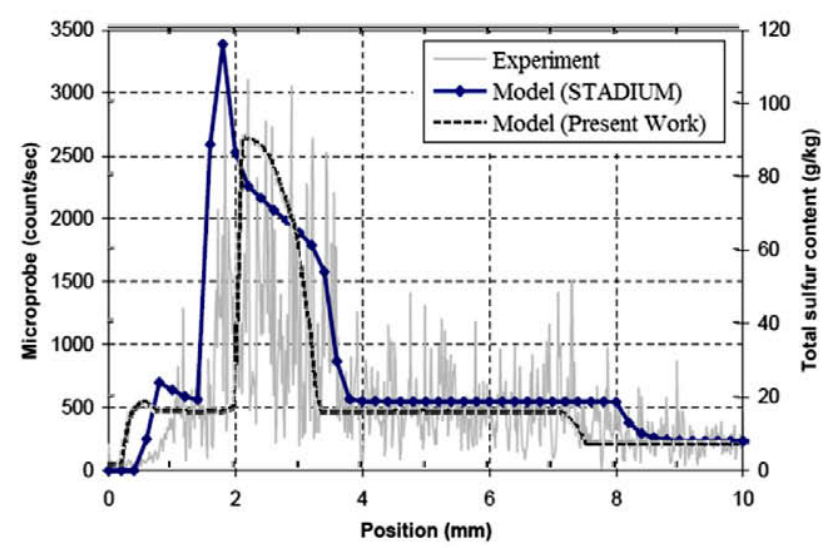

(d) Total sulfur profile

Fig. 8. (a), (b) - Total calcium and sulfur profiles in solid phases at the end of 6 months after Samson and Marchand [7]. (c), (d) - Total calcium and sulfur profiles in solid phases at the end of 1 year after Samson and Marchand [7].

simulated specimen is a US Type I cement mortar with porosity 0.3 , cement:water:sand mass ratio $1: 0.5: 3$, tortuosity 36 , density $1800 \mathrm{~kg} / \mathrm{m}^{3}$. The fraction of available porosity is assumed to be 0.2. The specimen is immersed in a $0.35 \mathrm{M} \mathrm{Na}_{2} \mathrm{SO}_{4}$ solution $(0.35 \mathrm{~mol} / \mathrm{L})$ and the solution is renewed every 7 days. The specimen is a $25 \mathrm{~mm} \times 25 \mathrm{~mm} \times 285 \mathrm{~mm}$ prism and the volume of the external solution is $1.78 \mathrm{~L}$ assuming the liquid to solid volume ratio to be 10. All six faces of the specimen are exposed to the external solution. This three-dimensional problem is chosen to represent real life cases. In most of the experiments found in the literature, a specimen is immersed in an aggressive solution where all the faces of the specimen are exposed to the solution. Also, all the real life cases are three-dimensional. The numerical model proposed in this paper is one-dimensional. If simulations are needed for such real cases, it is essential to idealize them as one-dimensional problems. Thus the actual three-dimensional problem is idealized to represent a one-dimensional problem as shown in Fig. 10. For simplicity of demonstration, the structure is assumed to be a cube having each side to be of length $L$. The structure is divided into $N$ hollow cubes (or shells) of thickness $d x$ starting from the outside towards the center of the specimen. The hollow cubes are labeled as A-D in Fig. 10a. The three-dimensional structure is idealized as a one-dimensional structure as shown in Fig. 10b. The area in contact with the external solution for the first element is $A=6 \mathrm{~L}^{2}$ and its volume is $V=A d x$. This constitutes the first element of the one-dimensional idealized structure which is labeled as A. The area of the second element is $A^{\prime}=6(L-d x)^{2}$ and its volume is $V=6(L-d x)^{2} d x$. This constitutes the second element of the idealized structure which is labeled as B. In this way, all the elements of the three-dimensional structure can be idealized to represent one-dimensional elements. The three-dimensional structure is exposed to the external solution on all sides whereas the idealized structure is exposed to the external solution only on one side as shown by the arrows in the figure. This process can be modified to idealize a prismatic shape as is used in this example problem.

Similar to the previous numerical simulation, the total available (i.e. readily leachable) concentrations of the different species were obtained for a Portland cement mortar from the LeachXS database.

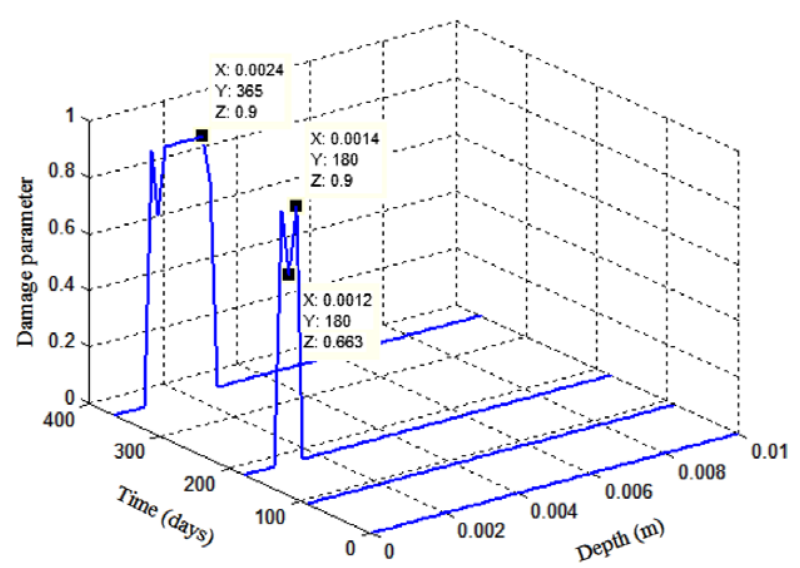

Fig. 9. Progression of damage parameter in time and space. 


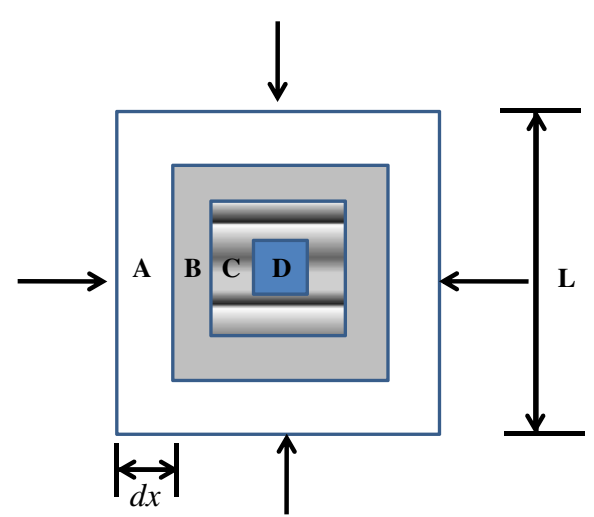

(a) Three dimensional structure

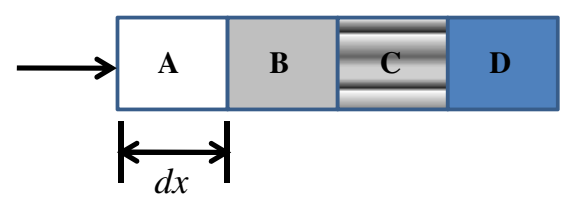

(b) One dimensional idealization

Fig. 10. One-dimensional idealization of a three-dimensional structure.

The available concentrations are lesser than the total concentrations of the species present in the system. The initial solid phase distribution along $25 \mathrm{~mm}$ dimension using the available concentrations of the ions is shown in Fig. 11a, where the $y$-axis is the amount of the indicated minerals in $\mathrm{g} / \mathrm{kg}$ of the total material and $x$-axis is the depth within the material from the face in $\mathrm{mm}$. Since the solid phase distribution is symmetrical about the center of the specimen, only a half-width is shown in the figures. It is important to note that the available concentration of Portlandite is more than that of CSH in Fig. 11a. Portlandite reacts/leaches more easily than CSH which starts reacting only when Portlandite is depleted from the system. Therefore, the available quantity of Portlandite as shown in Fig. 11a is most of the total quantity whereas the available concentration of $\mathrm{CSH}$ is a small fraction of the total quantity (available silicon concentration is $20 \%$ of the total quantity for this example problem).

The final solid phase distribution after 1 year of simulation is shown in Fig. 11b. The complete dissolution of hydrogarnet combined with sulfate ion ingress contribute to the increase in ettringite concentration. It is also evident from Fig. 11b that gypsum forms from Portlandite (calcium hydroxide) and sulfate ions (as shown in Eq. (1)) as the Portlandite dissolution front coincides with the gypsum formation front. Also, decalcification of CSH is seen by the dissolution of the Jennite-Tobermorite-II mixture as is expected when the structure is exposed to aggressive water [57-
59]. Fig. 11b also shows that at a depth up to approximately $0.5 \mathrm{~mm}$ ettringite is completely depleted. This is found to be due to the low $\mathrm{pH}$ value near the surface, which also corresponds with literature reports [6]. Thus, the mineralogical features of the cementitious materials under sulfate attack are reasonably simulated using the numerical model developed in this paper. The change in porosity due to the change in volume as a result of the chemical reactions is shown in Fig. 12. The initial decrease in porosity is due to the formation of gypsum and ettringite. As soon as the available porosity is filled up, strain starts to develop which leads to cracking of the structure. After a while, porosity increases when calcium starts to leach out to the surrounding solution.

Fig. 13 shows the progression of damage with time and space. Fig. 14 shows the damage front has progressed up to approximately $6 \mathrm{~mm}$ after 1 year. It is evident from Figs. 11b and 14 that the damage front is coincident with the gypsum progression front (end of the peak of Gypsum is approximately at $6 \mathrm{~mm}$ ). The calcium aluminate phase (for this case hydrogarnet phase) is completely consumed by sulfate to produce ettringite as can be observed in Fig. 11b. If ettringite had initiated damage, the front would have moved to the end of the structure which is not the case as can be seen in Fig. 14. As calcium hydroxide was available in the system, gypsum continued to form as sulfate ions continued to diffuse (refer to Eq. (1)). This corresponds to an increase in solid volume as can be seen from Table 1. This increase in volume leads to

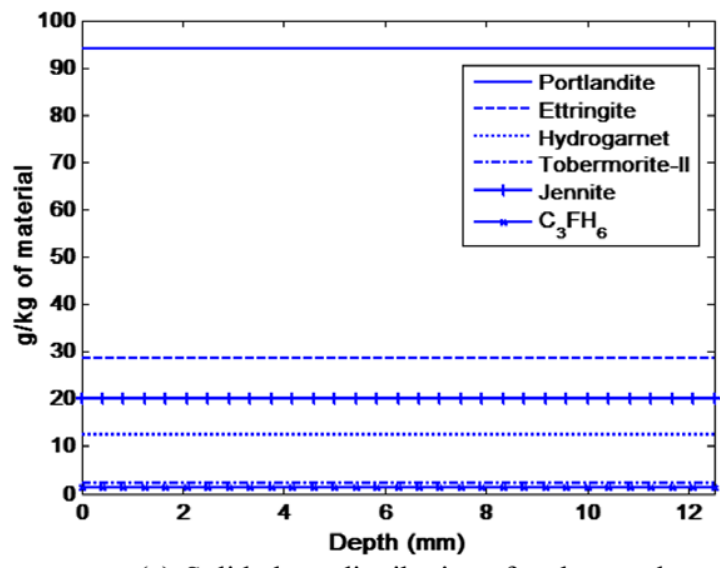

(a) Solid phase distribution of undamaged structure (initial condition)

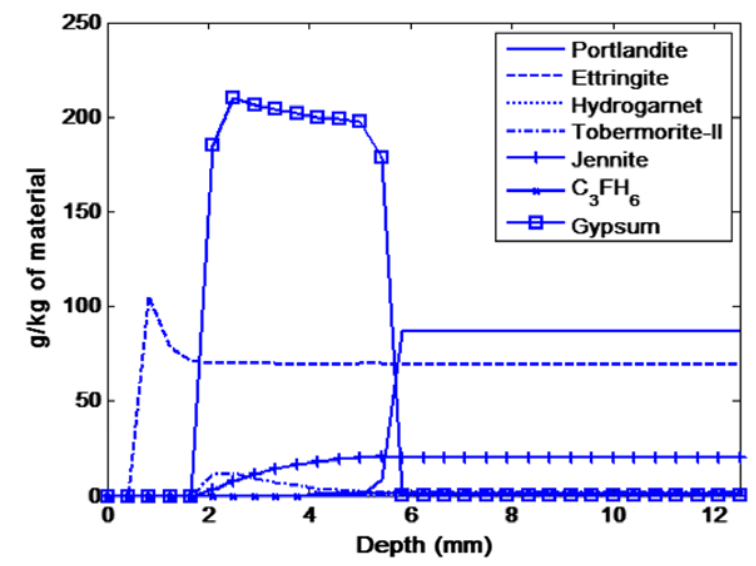

(b) Solid phase distribution after one year of simulation

Fig. 11. Distribution of the solid phases. 


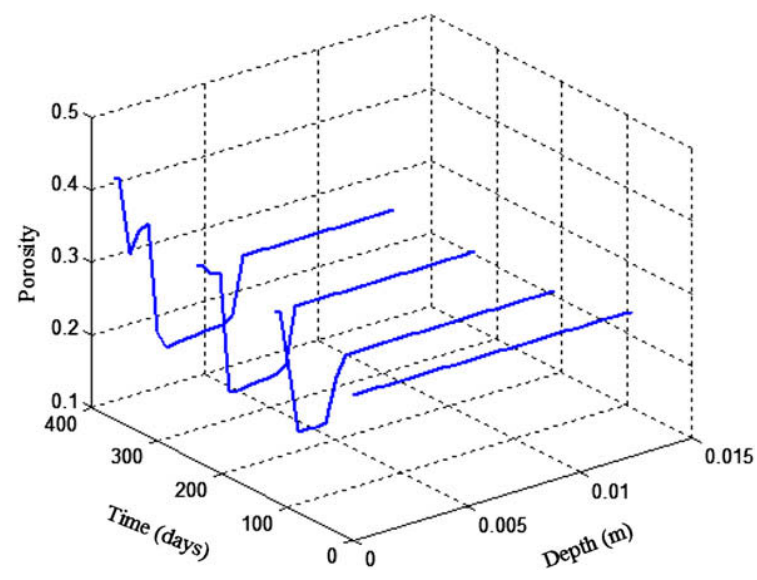

Fig. 12. Porosity profile with time and space.

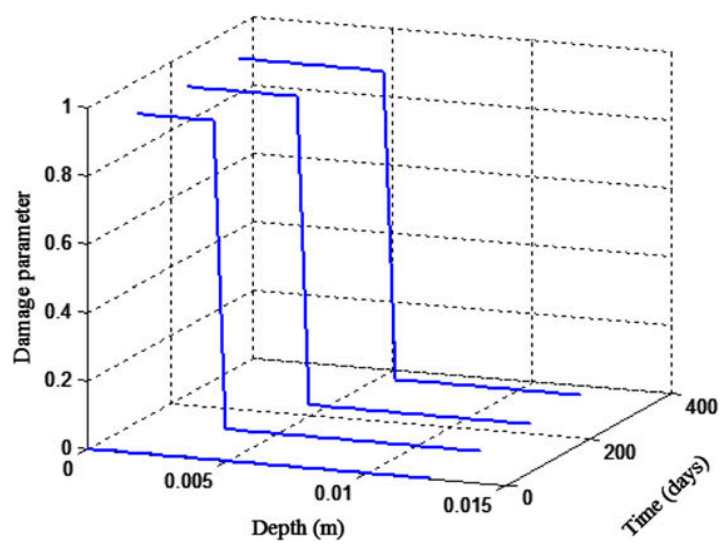

Fig. 13. Progression of damage parameter in time and space.

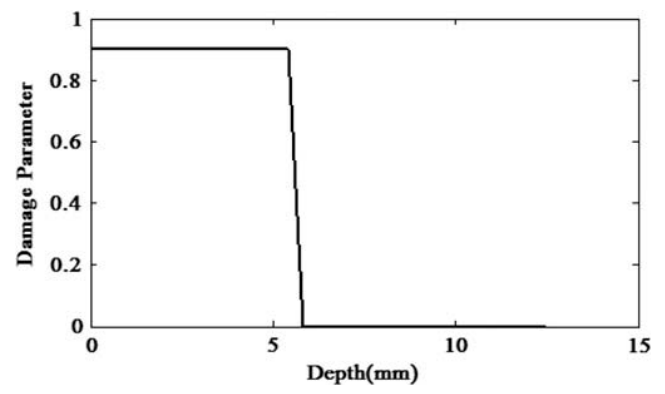

Fig. 14. Damage progression front at the end of 1 year.

strain and cracking. This indicates that gypsum is a prominent contributor of volumetric expansion [60] which was not included in the prior models as can be seen from Fig. 3.

As time progresses, the damage parameter increases with the increase in strain until it reaches the maximum value. The element is assumed to have failed when it reaches the completely cracked state characterized by the maximum damage parameter. Sulfate ions then diffuse in more rapidly through the cracks and more ettringite and gypsum are formed due to the chemical reactions, leading to failure of more elements. This increases the rate at which the damage front progresses. A failure criterion of the structure can be defined as the failure of all or some of the elements reaching the maximum damaged state. Finally, a time to failure of the structure can be obtained from the simulation. This type of simulation can be especially useful in design for durability as well as for inspection and maintenance scheduling.

\section{Conclusions}

A numerical model for assessing the degradation of cementitious materials under sulfate attack is developed in this paper. The model combines detailed approaches for the three essential components of degradation under sulfate attack: (1) multi-ionic diffusion under concentration and chemical activity gradients, (2) chemical equilibrium calculation to determine the amounts of dissolution and precipitation of solid products, and (3) assessment of the cracked state of the structure using a continuum damage mechanics model which affects further diffusion of the sulfate ions. The model is calibrated and validated using experimental results obtained from the literature. This model can be used to determine the profiles of the ions and the minerals as well as the progression of structural damage in time and space as shown in Section 4. Thus this model can potentially be applied for the assessment of longterm durability of cementitious structures. This model can also be used to evaluate the effect of initial composition of the cement paste on the damage progression of the structure and the variations in the aggressive solution due to leaching from the structure. Sensitivity analysis will be performed in a future work to address these issues.

\section{Acknowledgements}

This study is based on work supported by the US Department of Energy, under Cooperative Agreement Number DE-FC0106EW07053 entitled 'The Consortium for Risk Evaluation with Stakeholder Participation III' awarded to Vanderbilt University. The opinions, findings, conclusions, or recommendations expressed herein are those of the authors and do not necessarily represent the views of the Department of Energy or Vanderbilt University. The authors thank Dr. K. Brown of Vanderbilt University and Dr. C. Langton of Savannah River National Laboratory for their assistance during the development of this work.

\section{References}

[1] Phifer MA. Saltstone disposal facility mechanically stabilized earth vault closure cap degradation base case: institutional control to pine forest scenario (U). Savannah River Site: Washington Savannah River Company LLC; 2003.

[2] Langton CA. Analysis of saltstone pore solutions - PSU progress report IV, Aiken, South Carolina, E. I. du Pont de Nemours and Company; 1987.

[3] Clifton JR, Pommersheim JM. Sulfate attack of cementitious materials: volumetric relations and expansions, Gaithersburg (MD): Building and Fire Research Laboratory, National Institute of Standards and Technology; 1994.

[4] Naik NN, Jupe AC, Stock SR, Wilkinson AP, Lee PL, Kurtis KE. Sulfate attack monitored by microCT and EDXRD: influence of cement type, water-to-cement ratio, and aggregate. Cement Concrete Res 2006;36(1):144-59.

[5] Al-Dulaijan SU. Sulfate resistance of plain and blended cements exposed to magnesium sulfate solutions. Constr Build Mater 2007;21(8):1792-802.

[6] Wang JG. Sulfate attack on hardened cement paste. Cement Concrete Res 1994;24(4):735-42.

[7] Samson E, Marchand J. Modeling the transport of ions in unsaturated cementbased materials. Comput Struct 2007;85(23-24):1740-56.

[8] Tixier R, Mobasher B. Modeling of damage in cement-based materials subjected to external sulfate attack. I: formulation. J Mater Civil Eng 2003;15(4):305-13.

[9] Krajcinovic D, Basista M, Mallick K, Sumarac D. Chemo-micromechanics of brittle solids. J Mech Phys Solids 1992;40(5):965-90.

[10] ASTM. Standard test method for length change of hydraulic-cement mortars exposed to a sulfate solution. West Conshohocken (PA): ASTM International; 2004

[11] Atkinson A, Hearne JA. Mechanistic model for the durability of concrete barriers exposed to sulfate bearing groundwaters. Sci Basis Nuclear Waste Manage 1989;13:149-56.

[12] Basista M, Weglewski W. Micromechanical modeling of sulphate corrosion in concrete: influence of ettringite forming reaction. Theor Appl Mech 2008;35(1-3):29-52. 
[13] Snyder KA, Clifton JR. 4SIGHT manual: a computer program for modelling degradation of underground low level waste concrete vaults, Gaithersburg (MD): Building and Research Laboratory, National Institute of Standards and Technology; 1995.

[14] Brown PW, Taylor HFW. The role of ettringite in external sulfate attack. In Marchand J, Skalny JP, editors. Materials science of concrete: sulfate attack mechanisms. Westerbrook (OH): American Ceramic Society; 1999.

[15] Mindess S, Young JF. Concrete. New Jersey: Prentice Hall Inc.; 1981.

[16] Kurtis KE, Monteiro PJM, Brown JT, Meyer-Ilse W. Mechanism of concrete damage caused by sulfate attack examined through transmission X-ray microscopy, ALS compendium of user abstracts and technical reports; 1998.

[17] Diamond S. Delayed ettringite formation - processes and problems. Cement Concrete Compos 1996;18(3):205-15.

[18] Taylor HFW, Famy C, Scrivener KL. Delayed ettringite formation. Cement Concrete Res 2001;31(5):683-93.

[19] Tixier R, Mobasher B. Modeling of damage in cement-based materials subjected to external sulfate attack. II: comparison with experiments. J Mater Civil Eng 2003;15(4):314-22.

[20] Bary B. Simplified coupled chemo-mechanical modeling of cement pastes behavior subjected to combined leaching and external sulfate attack. Int J Numer Anal Methods Geomech 2008;32(14):1791-816.

[21] Saetta A, Scotta R, Vitaliani R. Mechanical behavior of concrete under physicalchemical attacks. J Eng Mech 1998;124(10):1100-9.

[22] Schmidt-Dohl F, Rostasy FS. A model for the calculation of combined chemical reactions and transport processes and its application to the corrosion of mineral-building materials Part I. Simulation model. Cement Concrete Res 1999;29(7):1039-45.

[23] Shazali MA, Baluch MH, Al-Gadhib AH. Predicting residual strength in unsaturated concrete exposed to sulfate attack. J Mater Civil Eng 2006;18(3):343-54.

[24] Samson E, Marchand J, Robert J-L, Bournazel J-P. Modelling ion diffusion mechanisms in porous media. Int J Numer Methods Eng 1999;46(12):2043-60.

[25] Marchand J, Samson E, Snyder KA, Beaudoin JJ. Ion transport mechanisms in unsaturated porous media: modeling. In: Hubbard AT, editor. Encyclopedia of surface and colloid science. Marcel Dekker; 2002.

[26] Samson E, Marchand J, Snyder KA, Beaudoin JJ. Modeling ion and fluid transport in unsaturated cement systems in isothermal conditions. Cemen Concrete Res 2005;35(1):141-53.

[27] Gospodinov PN, Kazandjiev RF, Mironova MK. The effect of sulfate ion diffusion on the structure of cement stone. Cement Concrete Compos 1996;18(6): 401-7.

[28] Ping X, Beaudoin JJ. Mechanism of sulphate expansion I. Thermodynamic principle of crystallization pressure. Cement Concrete Res 1992;22(4):631-40.

[29] Planel D, Sercombe J, Le Bescop P, Adenot F, Torrenti JM. Long-term performance of cement paste during combined calcium leaching-sulfate attack: kinetics and size effect. Cement Concrete Res 2006;36(1):137-43.

[30] Marchand J, Bentz DP, Samson E, Maltais Y. Influence of calcium hydroxide dissolution on the transport properties of hydrated cement systems. In: Skalny J, Gebauer J, Odler I, (Eds.), Materials science of concrete special volume: calcium hydroxide in concrete; 2001. p. 113-29.

[31] Ruthven DM. Principles of adsorption and adsorption processes. Wiley, John \& Sons, Incorporated; 1984

[32] Shen L, Chen Z. Critical review of the impact of tortuosity on diffusion. Chem Eng Sci 2007:62(14):3748-55.

[33] Samson E, Lemaire G, Marchand J, Beaudoin JJ. Modeling chemical activity effects in strong ionic solutions. Computat Mater Sci 1999;15:285-94.

[34] Marchand J, Samson E, Maltais Y, Beaudoin JJ. Theoretical analysis of the effect of weak sodium sulfate solutions on the durability of concrete. Cement Concrete Compos 2002;24(3-4):317-29.
[35] Meeussen JCL. ORCHESTRA: an object-oriented framework for implementing chemical equilibrium models. Environ Sci Technol 2003;37(6):1175-82.

[36] Gospodinov PN, Kazandjiev RF, Partalin TA, Mironova MK. Diffusion of sulfate ions into cement stone regarding simultaneous chemical reactions and resulting effects. Cement Concrete Res 1999;29(10):1591-6.

[37] Basista M, Weglewski W. Chemically assisted damage of concrete: a model of expansion under sulfate attack. Int J Damage Mech 2008.

[38] van der Sloot HA, Seignette P, Comans RNJ, van Zomeren A, Dijkstra JJ, Meeussen H, Kosson DS, Hjelmar O. Evaluation of environmental aspects of alternative materials using an integrated approach assisted by a database/ expert system. Advances in Waste Management and Recycling, Dundee, Scotland; 2003.

[39] Lothenbach B, Matschei T, Möschner G, Glasser FP. Thermodynamic modelling of the effect of temperature on the hydration and porosity of Portland cement. Cement Concrete Res 2008;38(1):1-18.

[40] Chesworth W. Encyclopedia of soil science. Springer; 2008.

[41] Scherer GW. Crystallization in pores. Cement Concrete Res 1999;29(8): 1347-58.

[42] Denham M. Thermodynamic and mass balance analysis of expansive phase precipitation in saltstone. Aiken (SC): Savannah River National Laboratory; 2008.

[43] Karihaloo BL. Fracture mechanics and structural concrete. Essex, England: Longman Scientific and Technical; 1995.

[44] Mazars J. A description of micro and macroscale damage of concrete structures. Eng Fract Mech 1986;25(5/6):729-37.

[45] Tao X, Phillips DV. A simplified isotropic damage model for concrete under biaxial stress states. Cement Concrete Compos 2005;27(6):716-26.

[46] Labadi Y, Hannachi NE. Numerical simulation of brittle damage in concrete specimens. Strength Mater 2005;37(3):268-81.

[47] di Prisco JMM. Crush-crack': a non-local damage model for concrete. Mech Cohes-Frict Mater 1996;1(4):321-47.

[48] Scotta R, Vitaliani R, Saetta A, Onate E, Hanganu A. A scalar damage model with a shear retention factor for the analysis of reinforced concrete structures: theory and validation. Comput Struct 2001;79(7):737-55.

[49] Budiansky B, O'Connell R. Elastic moduli of a cracked solid. Int J Solids Struct 1976;12:81-97.

[50] Nemat-Nasser S, Hori M. Micromechanics: overall properties of heterogeneous materials. New York: North-Holland; 1993.

[51] Krajcinovic D. Effective material properties in the limit of large defect concentration. Eng Fract Mech 1997:57(2-3):227-40.

[52] Stauffer D, Aharony A. Introduction to percolation theory. Philadelphia (PA): Taylor \& Francis Ltd.; 2003.

[53] Charlaix E. Percolation threshold of a random array of discs: a numerical simulation. J Phys A: Math Gen 1986;19(9):L533-6.

[54] Sornette D. Critical transport and failure in continuum crack percolation. J Phys 1988;49:1365-77.

[55] Marchand J. Modeling the behavior of unsaturated cement systems exposed to aggressive chemical environments. Mater Struc 2001;34(4):195-200.

[56] Meeussen JCL. How to include a solid solution in ORCHESTRA calculations; 2009. <http://www.meeussen.nl/orchestra/examples/solidsolution/>.

[57] Gerard B, Bellego CL, Bernard O. Simplified modelling of calcium leaching of concrete in various environments. Mater Struct 2002;35(10):632-40.

[58] Le Bellego C, Gerard B, Pijaudier-Cabot G. Chemo-mechanical effects in mortar beams subjected to water hydrolysis. J Eng Mech 2000;126(3):266-72.

[59] Cao HT, Bucea L, Ray A, Yozghatlian S. The effect of cement composition and $\mathrm{pH}$ of environment on sulfate resistance of Portland cements and blended cements. Cement Concrete Compos 1997;19(2):161-71.

[60] Tian B, Cohen MD. Does gypsum formation during sulfate attack on concrete lead to expansion? Cement Concrete Res 2000;30(1):117-23. 